\title{
Implementation of the Evaluation System of Coastline Change and Stability on Yellow River Estuary
}

\author{
YANG Hai-bo, WANG Yuan \\ School of Water Conservancy and Environment, Zhengzhou \\ University \\ Zhengzhou, China \\ zzutyhb@163.com
}

\author{
Wei Jia-hua \\ State key Laboratory of Hydroscience and Engineering, \\ Tsinghua University \\ Beijing, China \\ weijiahua@mail.tsinghua.edu.cn
}

\begin{abstract}
By using TM/ETM+ images of Yellow River estuary from 1989 to 2001, the coastlines of different terms are detected on the base of multi-coordinate system method. Each coastline is divided into 24 sections to analyze the Yellow River estuary change carefully in a smaller scale. Then the yellow river estuary stability is evaluated after the average annual variation rate and average annual distance migration rate are constructed and calculated. Finally, the application system are developed.
\end{abstract}

Key words - coastline change, Yellow River Estuary, stability evaluation, GIS, RS.

\section{INTRODUCTION}

The Yellow River is the largest sediment concentration river in the world, and which made the coastline of the Yellow River change greatly [1]. At present, the key is governance estuary, stabilizing the current Yellow River way flows into the sea and controlling tail river natural swing, then ensure delta have a stable construction and investment environment [2]. Research on the Yellow River estuary has been for many years, Wang Yanhong (2003) analyzed the morphology evolution and formation mechanism of the muddy coast, and pointed out that there was a transitional coast from deposition to erosion, between silting and erosion coast. Chen Shenliang (2005) describes the Feiyantan waters of beach erosion characteristics and landscape changes after Diaokou river abandoned according to the terrain and cross-sectional depth of water monitoring data.

Remote sensing technology has the features of macroscopic, continuous, real-time, est. Using remote sensing technology to monitor the coast of the Yellow River mouth can get a wide range of real-time coast circumstances. It can master the coast of Change and Stability comparing to data of many years [3]. Research and applications show that the TM / ETM satellite remote sensing technology can realize real-time dynamic monitoring of the Yellow River estuary coastal, and it's Significant in aspects of the effect of the dynamic monitoring and prediction of coastal change [4].

Against above problems, applying remote sensing and GIS technology, design and develop the Yellow River Estuary
Coastal Change and Stability Evaluation System. The system uses remote sensing images for real-time monitoring of the Yellow River estuary coastal, be able to analyze certain period of time a regional coast type of change, the magnitude of change and migration distance data. It also can predict the estuary area change information based on runoff, sediment concentration and other information, visualize monitoring and prediction results in text and graphics, show to the users intuitively, vividly, and fast.

\section{RESEARCH METHODS}

\section{A. Research Area and Data}

Yellow River Delta is taken as the study area, which lies at longitude $118^{\circ} 7^{\prime}-119^{\circ} 10^{\prime} \mathrm{E}$ and latitude $37^{\circ} 20^{\prime}-38^{\circ} 10^{\prime} \mathrm{N}$. Landsat TM/ETM+ images from 1989 to 2001 are used. We firstly rectify the image of 1989 using geography map of $1: 100000$, then image registration is applied to the images of 1995 and 1999 with the image of 1989 rectified. Finally the enhancement process is used to improve the image interpretation

\section{B. Research Methods}

\section{1) Coastline Extraction}

The method of shoreline monitoring is coastline extraction. In the process, first, access every pixel value by sub-block reading the remote sensing image, then calculate the value of NDWI to distinguish between water bodies and land, the algorithm is

NDWI=(ETM2-ETM4)/(ETM2+ETM4).

Set the lower threshold $\mathrm{K}$ after obtaining NDVI index. With reference to the relevant literature and repeated experiments, the best water extraction determine $\mathrm{K}>0.1$ [5-6]. Next, give the pixel value of water as 255 , the pixel value of land as 0 , the one of $($ ETM $2+E T M 4)=0$ corresponding. And in accordance with the process in the pixel line by line scan coastline, then eliminate the land border block produced. Finally get the coastline extraction results.

2) Coastline analysis 
In the function of coastline analysis, owing to coastline near the Yellow River estuary silting and eroding retreat alternating and coastline's different variation, we adopt a new method based on GIS overlay analysis--- coastline Analysis of multicoordinate system. In order to ensure the accuracy of analysis, establish three coordinate system $(\mathrm{A}, \mathrm{B}, \mathrm{C})$ within the scope of analysis (estuary coastline), corresponding to the three subanalysis range(Figure 1). These three coordinate systems are divided to 36 regions at equal angles $\left(10^{\circ}\right.$ ) (except for the last area of the $\mathrm{C}$ coordinate system), and the coastline is also divided into 36 segments within the scope of analysis, so that sub-analyze coastline. Through the observation of the change on the continuous years of coastline, discover the change of some adjacent coastline is consistent, they are together and analyzed integrally. Eventually the coastline is divided into 24 sections (Figure 4).

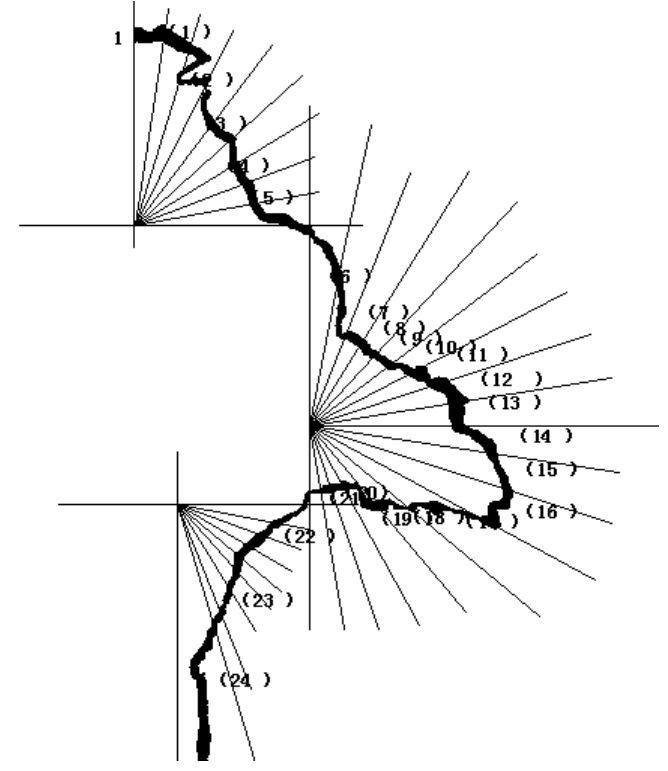

Fig. 1. Establishing Multi-coordinate system

User to select the time period to be analyzed, the system will automatically analyze, based on the time period of coastline changes, using of superposition analysis of spatial analysis function, in a very short period of time, can get the change type, the coastline change amplitude, coastline migration distance, average annual variation rate and average annual distance migration rate, in order to prepare data for stability evaluation.

Spatial analysis here mainly use the coordinate system layers and each year the coastline layer, different years of coastlines have different intersection with coordinate, that is, each coordinate line can be cut into segments of different lengths, the corresponding results can be obtained by the operator corresponding to the respective length of the segment. Mark the length of the coordinate line intercepted by the coastline of ending year for $\mathrm{C}_{\text {end }}$, the length of the coordinate line intercepted by the coastline of starting year for $\mathrm{C}_{\text {begin }}$ (the following $\mathrm{C}_{\text {end }}$ and $\mathrm{C}_{\text {begin }}$ are the same corresponding period of coastline). The shoreline change type is based on the value of
$\left(\mathrm{C}_{\text {end }}-\mathrm{C}_{\text {begin }}\right)$, if plus, it's silting coastline, if minus, it's erosive coast. Calculation formula for coastline change amplitude is

$$
\mathrm{CCA}=\mathrm{C}_{\text {end }}-\mathrm{C}_{\text {begin }} \text {. }
$$

Coastline migration distance is the absolute value's sum of the coordinate line length's difference of adjacent years from starting year to ending year, namely,

$$
\mathrm{CMD}=\left|\mathrm{C}_{\text {begin }}-\mathrm{C} 1\right|+|\mathrm{C} 1-\mathrm{C} 2|+\ldots+\left|\mathrm{Cn}-\mathrm{C}_{\text {end }}\right| \text {. }
$$

The average annual variation rate $\mathrm{AAVR}=\mathrm{CCA} /$ (ending year -starting year). The average annual distance migration rate $\mathrm{AADMR}=\mathrm{CMD} /$ (ending year - starting year).

\section{3) Coast Stability Evaluation}

First, determine the impact indicators of the coastal stabilization level, which is each section of coast's change amplitude $\mathrm{CCA}\left(\mathrm{CCA}=\mathrm{C}_{\text {end }}-\mathrm{C}_{\text {begin }}\right)$ and the ratio of coast change amplitude and coast migration distance $\alpha(\alpha=\mathrm{CCA} / \mathrm{CMD})$, thereinto, change amplitude $\mathrm{S}$ reflect the overall change degree of the section coast in a certain period of time, and the ratio $\alpha$ reflect the swing degree of the section coast(the alternate frequency of siltation and erosion). According to some relevant data in the function of coastline analysis, formulate grading standard g1 and g2 for each section of coast's change amplitude $\mathrm{S}$ and ratio $\alpha(\mathrm{g} 1$ and $\mathrm{g} 2$ as shown in Table 1).

Next, determine the two impact indicators' weights, according to the description of relevant literature about Yellow River estuary, where, W1 $=0.36, \mathrm{~W} 2=0.64$.

Finally, based on the formula

$$
\mathrm{G}=\mathrm{g} 1 * \mathrm{~W} 1+\mathrm{g} 2 * \mathrm{~W} 2 \text {, }
$$

scientific and quantitatively reach the grade of coast stability $G$, then assess the stability of the level L of each section of coast in accordance with the stability level

\begin{tabular}{|c|c|c|c|c|c|}
\hline $\begin{array}{l}\text { coastline } \\
\text { change } \\
\text { amplitude }(C C A)\end{array}$ & $\begin{array}{l}\text { Grad } \\
e \\
(g 1)\end{array}$ & $\begin{array}{l}\text { ratio of coast } \\
\text { change } \\
\text { amplitude and } \\
\text { migration } \\
\text { distance }(\alpha)\end{array}$ & $\begin{array}{l}\text { Gra } \\
\text { de }(g \\
2)\end{array}$ & $\begin{array}{l}\text { grade of } \\
\text { coast } \\
\text { stability }(G)\end{array}$ & $\begin{array}{l}\text { Grade( } \\
\text { L) }\end{array}$ \\
\hline $\mathrm{CCA}<=1000$ & 5 & $\alpha<=0.1$ & 5 & $\mathrm{G}<=2.5$ & I \\
\hline $\begin{array}{c}1000<\mathrm{CCA}<= \\
1500\end{array}$ & 4 & $0.1<\alpha<=0.25$ & 4 & $2.5<G<=2.8$ & II \\
\hline $\begin{array}{c}1500<\mathrm{CCA}<= \\
3000\end{array}$ & 3 & $\begin{array}{c}0.25<\alpha<=0.3 \\
5\end{array}$ & 3 & $2.8<\mathrm{G}<=3.2$ & III \\
\hline $\begin{array}{c}3000<\mathrm{CCA}<= \\
4000\end{array}$ & 2 & $0.35<\alpha<=0.5$ & 2 & $3.2<\mathrm{G}<=4$ & IV \\
\hline CCA $>4000$ & 1 & $A>0.5$ & 1 & $\mathrm{G}>4$ & V \\
\hline
\end{tabular}
evaluation criteria.

TABLE I. CoAst Stability EVALUATION CRiteria

\section{System Development Framework and Function}

The system based on the powerful function of interface MapGIS development platform to provide, applying GIS and database technology, using $\mathrm{C} / \mathrm{S}$ mode and $\mathrm{C} \#$ language for secondary development, constructed a platform for analysis, forecasting dynamic transformation and the coast of the Yellow River estuary coastline stability evaluation. The system consists of the basic functions of subsystems, data query and forecast subsystem, coastline monitoring and analysis subsystem, coastline stability evaluation subsystem and threedimensional operation subsystems. Its core functions are 
coastline monitoring and analysis, the coastline stability evaluation and three-dimensional operations. The main menu and the overall framework are shown in Figure 2:

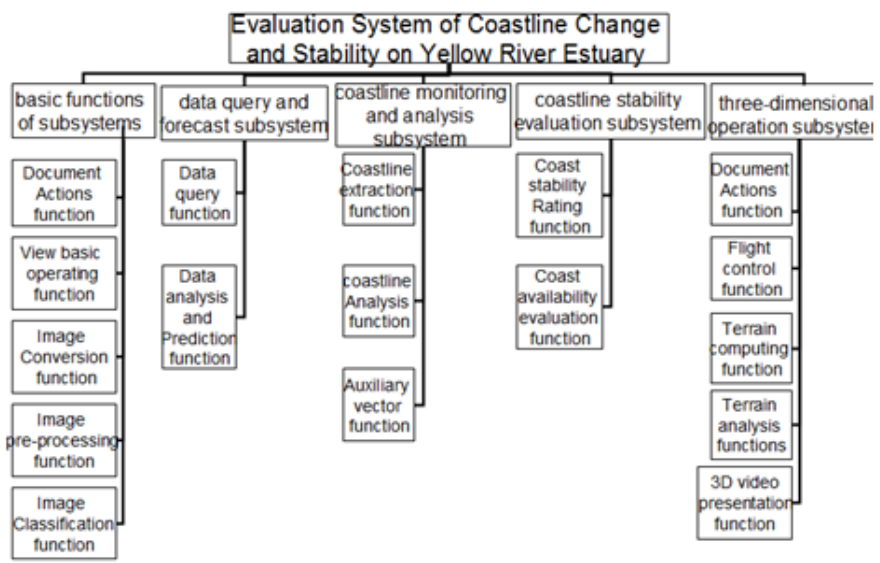

Fig. 2. system main menu and overall framework

\section{RESULTS}

\section{A. Coastline Change Analysis}

After the analysis process, the image of the corresponding time period can be displayed in the left view of the box(Figure $3)$.

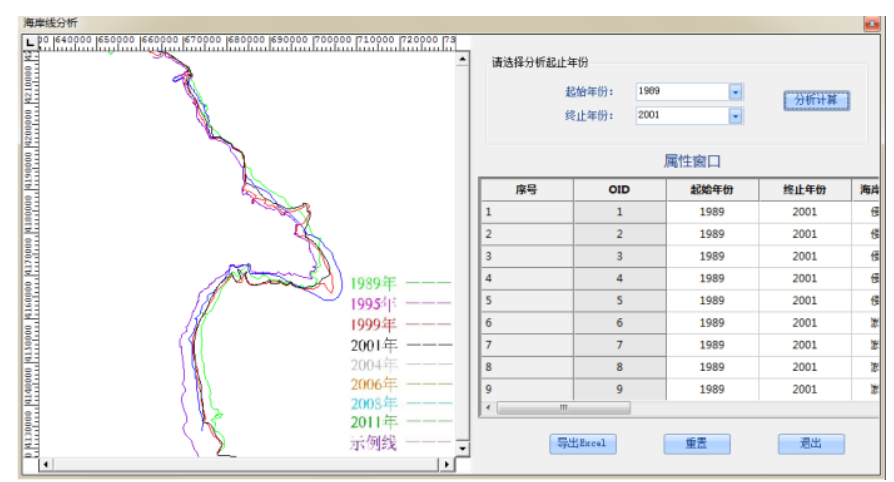

Fig. 3. Results Of Coastline Analysis

The figure analyzes the coastline from 1989 to 2001, get the analysis results from 1989 to 2001 (Chart 2). Here $C_{\text {end }}$ is the length of the coordinate line intercepted by coastline of $2001, C_{\text {begin }^{n}}$ is the length of the coordinate line intercepted by coastline of 1989. According to the principle of coastline analysis, the $6^{\text {th }}, 7^{\text {th }}, 8^{\text {th }}, 9^{\text {th }}, 10^{\text {th }}, 11^{\text {th }}, 12^{\text {th }}, 13^{\text {th }}, 14^{\text {th }}$, and $17^{\text {th }}$ section of coastlines is siltation coast, while the $1^{\text {st }}, 2^{\text {nd }}, 3^{\text {rd }}, 4$ th $, 5^{\text {th }}, 15^{\text {th }}, 16^{\text {th }}, 18^{\text {th }}, 19^{\text {th }}, 20^{\text {th }}, 21^{\text {th }}, 22^{\text {th }}, 23^{\text {th }}$ and $24^{\text {th }}$ section of coastlines is erosive coast. Then take the first section of coastline for example, its coastline change amplitude (CCA) is -427.935 meters. The coastline migration distance (CMD) is 2023.191 meters. The average annual variation rate (AAVR) is -23.774 meters per year. The average annual distance migration rate(AADMR) is 112.4 meters per year. The results of the remaining segment of coastline are similar with first segment. Other segments as shown in Table 2.

TABLE II. ANALysis RESUlts From 1989 To 2001

\begin{tabular}{|c|c|l|l|l|l|}
\hline \multicolumn{6}{|c|}{ Coastline change analysis from 1989 to 2001 } \\
\hline $\begin{array}{l}\text { segm } \\
\text { ent }\end{array}$ & $\begin{array}{l}\text { Type of } \\
\text { coastlin } \\
\text { e } \\
\text { change }\end{array}$ & $\begin{array}{l}\text { coastline } \\
\text { change } \\
\text { amplitude/ } \\
\boldsymbol{m}\end{array}$ & $\begin{array}{l}\text { coastline } \\
\text { migration } \\
\text { distance/m }\end{array}$ & $\begin{array}{l}\text { average } \\
\text { annual } \\
\text { variation } \\
\text { rate/m/year }\end{array}$ & $\begin{array}{l}\text { average } \\
\text { annual } \\
\text { distance } \\
\text { migration } \\
\text { rate/m/year }\end{array}$ \\
\hline 1 & $\mathrm{~A}$ & -427.935 & 2023.191 & -23.774 & 112.4 \\
\hline$\ldots$ & $\ldots$ & $\ldots$ & $\ldots$ & $\ldots$ & $\ldots$ \\
\hline 6 & $\mathrm{~B}$ & 213.879 & 7289.646 & 11.882 & 404.98 \\
\hline$\ldots$ & $\ldots$ & $\ldots$ & $\ldots$ & $\ldots$ & $\ldots$ \\
\hline 24 & $\mathrm{~A}$ & -1065.151 & 1474.843 & -59.175 & 81.936 \\
\hline
\end{tabular}

\section{B. Coast Stability Evaluation}

After the above processing, the results are visualized display (Figure 4). The figure evaluate the coastline of the period from 1989 to 2001, in the results view can show stable level of every section of coast, and displayed in different colors, including the overall evaluation of the coast, segmented evaluation and utilization assessment of each section of coast.

From 1989 to 2001 , the $1^{\text {st }}, 2^{\text {nd }}, 3^{\text {rd }}, 4^{\text {th }}, 5^{\text {th }}, 15^{\text {th }}, 16^{\text {th }}, 18^{\text {th }}$, $19^{\text {th }}, 20^{\text {th }}, 21^{\text {st }}, 22^{\text {nd }}, 23^{\text {rd }}$ and $24^{\text {th }}$ sections of the Yellow River estuary coasts are erosive coast, and the $6^{\text {th }}, 7^{\text {th }}, 8^{\text {th }}, 9^{\text {th }}, 10^{\text {th }}$, $11^{\text {th }}, 12^{\text {th }}, 13^{\text {th }}, 14^{\text {th }}$ and $17^{\text {th }}$ sections are siltation coast.

Thereinto, the stability level of the $5^{\text {th }}, 6^{\text {th }}, 7^{\text {th }}, 12^{\text {th }}, 13^{\text {th }}$, $14^{\text {th }}, 15^{\text {th }}, 16^{\text {th }}, 17^{\text {th }}, 20^{\text {th }}, 22^{\text {nd }}$ and $23^{\text {rd }}$ sections of coasts is I . These sections of coasts with the feature of very high frequency of coastline fluctuations, quite poor stability and greatly low land use efficiency, are not badly suitable for development and utilization.

The stability level of the $11^{\text {th }}$ and $19^{\text {th }}$ sections of coasts is II, These sections of coasts with the feature of high frequency of coast fluctuations, poor stability and low land use efficiency, are not also suitable for development and utilization.

The stability level of the $1^{\text {st }}, 2^{\text {nd }}, 10^{\text {th }}$, and $18^{\text {th }}$ sections of coasts is III. Coast's fluctuation frequency is general, and stability is medium, but the $1^{\text {st }}, 2^{\text {nd }}$ and $18^{\text {th }}$ sections are erosive coast, which aren't suitable for development and utilization. While the $10^{\text {th }}$ section of coast is siltation coast, and its land use efficiency is medium, so it can be used as appropriate according to the actual situation.

The stability level of the $3^{\text {rd }}, 4^{\text {th }}, 8^{\text {th }}, 9^{\text {th }}$ and $21^{\text {st }}$ sections of coasts is IV, these sections of coasts' fluctuation frequency is low, and stability is high, but the $3^{\text {rd }}, 4^{\text {th }}$ and $21^{\text {st }}$ sections of coasts are erosive coast, it's cautious of development and utilization. The $8^{\text {th }}$ and $9^{\text {th }}$ sections are siltation coast, and its land use efficiency is high, so that they can be used.

The stability level of the $24^{\text {th }}$ section of coast is $\mathrm{V}$, its fluctuation frequency is very low, and stability is pretty good, however, the section of coast is erosive coast, so be only used as appropriate according to the actual situation.

According to revelant data, the results of the evaluation are very consistent with the actual situation. 


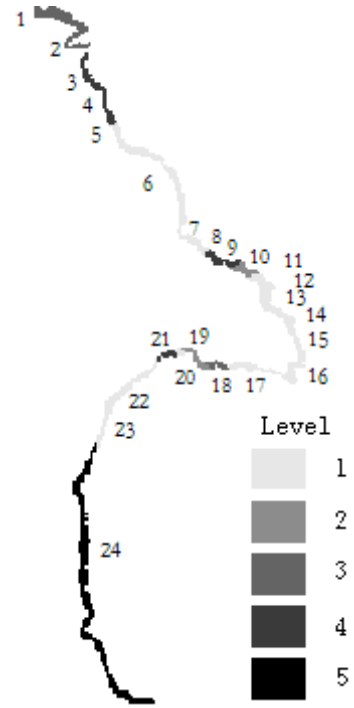

Fig. 4. Coast Stability Evaluation result

\section{CONCLUSIONS}

The evaluation system of coastline change and stability on Yellow River Estuary combines with GIS and RS, makes full use of the advantages of TM/ETM data, realize the real-time monitoring and analysis and evaluation on Yellow River Estuary, and solve some problems in the coastal monitoring, provide some technical support for coastal monitoring, analysis and evaluation, and open up a new way for the future development of coastal monitoring technology.

\section{ACKNOWLEDGMENT}

This work was financially supported by Open Research Fund Program of State key Laboratory of Hydroscience and Engineering (sklhse-2012-B-03).

\section{REFERENCES}

[1] Chang Jun, Dynamic Monitoring and simulation and prediction of Yellow River Delta coastline Based on RS and GIS . Shandong Normal University. 2001,(01)

[2] Cui Buli, Chang Xueli, Chen Yalin, Dong Qiong, Li Weiqing. Influence of the Yellow River hydrological characteristics of estuarine and coastal change. 2006,(06):957-958

[3] Yang Ming, Yu Xuchu, Wu Hanshu, Wang Chao, Lin Bin. Study on the hyperspectral image locally linear embedding algorithm for classification..2012,178(04):33-35

[4] Zhang Shuqin. Based on RS and GIS Modern Yellow River Delta coastal erosion silt variation and prediction. China University of Petroleum. 2009,(06)

[5] Weng Yongling, Tian Qingjiu. Remote Sensing Data Fusion Analysis and Evaluation Summary. Remote Sensing Information 2003:45-52

[6] Tong Hengjian, Huang Hong, Zuo Boxin. Multi-band remote sensing image data organization and publishing. Earth Science China University of Geosciences. 2012(3):587-592 